\title{
Endoscopic management of infantile non atretic nasal obstruction
}

\section{Original Article}

\author{
Eladl, Hesham Mohamed, Khafagy, Yasser W. \\ ORL Department, Mansoura University, Egypt
}

\begin{abstract}
Objective of the study: Evaluate some of the non atretic indications for endoscopic infantile nasal surgery regarding surgical technique, safety, and success.

Patients and Methods: Retrospective analysis of 14 infants required endoscopic nasal surgery for severe non atretic nasal blockage in ORL department mansoura university hospital between 2010 and 2017, their age ranged between 1 month and 19 months, 8 female and 6 males. The indications were nasal obstruction due to craniofacial anomaly (Cruozon syndrome) 3 cases, post traumatic nasal adhesions 10 cases, and congenital pyriform aperture stenosis in 1 case. Endoscopic nasal surgery was conducted to perform widening of the nasal airway through bilateral partial inferior turbinectomy in Cruozon syndrome, nasal adhesolysis with or without stenting in post traumatic nasal adhesions, or trans nasal correction of pyriform aperture stenosis.

Results: All patients showed postoperative improvement without restenosis or complications during follow up period in all study groups, only one patient of nasal adhesions group showed restenosis and didn't complete the follow up.

Conclusion: TVarious non atretic indications for infantile endoscopic surgery as nasal adhesions, nasal obstruction in crouzon syndrome and CPAS could properly managed with endoscopic surgery. Careful management of nasal obstruction during neonatal care with delicate handling is very important to avoid unnecessary complications as nasal adhesions. Proper knowledge and experience with endoscopic surgery in this age is mandatory regarding the preoperative preparation and planning, operative technique, and post operative follow up. The technique is challenging and required good experience yet it is rewarding and mostly successful.
\end{abstract}

Key Words: Endoscopic, infant, nasal obstruction, nasal stenosis, neonatal

Received: 15 March 2018, Accepted: 30 May 2018

Corresponding Author: Eladl, Hesham Mohamed, Tel.: 002502348787, E-mail: heshameladl@mans.edu.eg

ISSN: 2090-0740, June 2018, Vol.19, No.2

\section{INTRODUCTION}

Auditory Neonatal and infantile upper airway obstruction may be life threatening, and showed difficulty in diagnosis and management ${ }^{[1]}$. Although the main cause of nasal obstruction in infants is rhinitis, other aetiology as congenital, iatrogenic, or neoplastic disease should considered $^{[2]}$.

Upper airway obstruction and respiratory distress is common in Crouzon syndrome ${ }^{[3]}$. Iatrogenic nasal vestibular stenosis is rare complication during neonatal care $^{[4]}$.

Congenital stenosis of the pyriform aperture (CNPS) is an uncommon etiology of neonatal nasal obstruction. Neonates are exclusive nasal breathers, hence proper early diagnosis and management are very important and could be life saving. Difficulty in passing a probe of $2.8 \mathrm{~mm}$ through anterior nares is highly suspicious for diagnosis of (CNPS $)^{[5]}$.

\section{OBJECTIVE OF THE STUDY:}

Evaluate some of the non atretic indications for endoscopic infantile nasal surgery regarding surgical technique, safety, and success.

\section{PATIENTS AND METHODS:}

Retrospective analysis of 14 infants required endoscopic nasal surgery for severe non atretic nasal blockage in ORL department mansoura university hospital between 2010 and 2017 [our experience with choanal atresia was previously published $\left.{ }^{[6]}\right]$, their age ranged between 1 month and 19 months, 8 female and 6 males. The indications were nasal obstruction due to craniofacial anomaly (Cruozon syndrome) 3 cases, post traumatic (iaterogenic) nasal adhesions 10 cases, and congenital nasal pyriform aperture stenosis 1 case (table 1). The study was conducted after approval of institutional review board. Consents were taken from the parents after proper explanation of the disease and management plane. 


\section{Evaluation}

All patients were evaluated clinically, fiberoptic nasal endoscopy, and radiologically (plain x-ray nasopharynx lateral view soft as adenoids is a common finding, CT parnasal sinus (axial and coronal cuts).

\section{Options of treatments and counseling}

Many cases are expected to improve with growth overtime. Assurance for the parents is very helpful with watchful waiting. Medical treatment as saline nasal wash and careful suction is helpful in many cases to relieve obstruction and inflammation. Nasal decongestants and steroids, is not recommended unless under good medical supervision before age of 2 years to avoid complications.

Planning for surgical treatment with good counseling for the parents is crucial in this age group. Surgeon should explain the procedure plan, operative risks, post operative follow up plane, and complications. Most of endoscopic procedures in this age group required lengthy follow up with a possibility of second look procedures. Enlarged adenoid should not overlook during infantile endoscopic sinus surgery.

\section{Technique}

Infantile endoscopic nasal surgery required meticulous maneuver with the use of sizable instruments (micro otologic instruments are frequently needed). Surgeon should have good experience in pediatric endoscopic sinonasal surgery difficulties regarding anatomy, technique, and follow up. Although, most of the procedures in infantile endoscopic nasal surgery are simple yet good training and learning curve is required to avoid unnecessary complications. Zero degree endoscope with 4, $2.7 \mathrm{~mm}$ diameter should be available. $4 \mathrm{~mm}$ endoscope gives better angle of view and better surgical performance. Avoid extensive tissue injury or extensive cauterization during surgery was considered. Also, good homeostasis without nasal packing was performed in all patients.

\section{Cruozon syndrome}

3 cases of Cruozon syndrome were presented with complete bilateral nasal blockage and frequent apnea (table 1). CT showed narrow nasal airway, no significant air inside nasal airway without atresia. Endoscopic nasal surgery was conducted to perform widening of the nasal airway through bilateral partial inferior turbinectomy with adenoidectomy. Avoid extensive removal of turbinate tissue anteriorly or extensive cauterization. Turbinate tissue was mostly bony with limited soft tissue growth and required sharp cutting in good surgical plane to avoid bleeding, extensive mucosal injury, and scaring (figure 1). Endoscopic assisted adenoidectomy was conducted in the same sitting in the 3 patients (figure 2).

\section{Post traumatic nasal adhesions and stenosis}

Ten cases of post traumatic nasal adhesions, their age ranged between one month and 19 months (table 1). All infants had nasal maneuvers (nasogastric feeding, nasal suctioning and nasal continuous positive airway pressure) during their neonatal care in pediatric department. Clinical picture was bilateral nasal blockage ${ }^{[10]}$, sleep difficulties and $\mathrm{OSAS}^{[10]}$, failure to thrive ${ }^{[8]}$. Incomplete nasal adhesions were situated between inferior turbinate and nasal septum. Nasal adhesions were complete unilateral in 3 cases involving whole length of the nasal cavity. Unilateral choanal stenosis and unilateral alar collapse was encountered in one case with complete nasal adhesion. Endoscopic nasal adhesolysis was done using coblation needle and or bipolar diathermy without extensive cauterization. Correction of any associated pathology was done in the same sitting (6 cases required endoscopic assisted adenoidectomy). Alar collapse was improved after adhesolysis. Silicone sheet stents were used in case of complete and or anterior adhesions (4 cases) to avoid post operative scarring and vestibular adhesions (figure 3). Second look endoscopy was done in 6 patients to assess the airway.

\section{Congenital nasal pyriform aperture stenosis (CNPS)}

One infant with CNPS was included in the study, aged 3 months. Clinically, patient showed severe nasal blockage, feeding and sleeping difficulties. CT paranasal sinus showed narrow pyriform aperture (less than $4 \mathrm{~mm}$ ). Endoscopic trans nasal approach correction was done through minute incision anterior to inferior turbinate with submucosal drilling and widning of the pyriform aperture. No nasal pack or stent were used in the procedure. Second look endoscopy was done 6 weeks postoperatively and showed no restenosis.

\section{RESULTS}

All patients showed postoperative improvement without restenosis or complications during follow up period in all study groups (cruozon syndrome, post traumatic nasal adhesions, congenital nasal pyriform aperture stenosis), only one patient of nasal adhesions showed restenosis and didn't complete the follow up (table 1). 
Eladl and khafagy

Table 1: study group variables

\begin{tabular}{|c|c|c|c|c|c|c|c|}
\hline number & Disease & Age & Sex & Adenoid & $\begin{array}{l}\text { Associated } \\
\text { disease }\end{array}$ & stenting & recurrence \\
\hline 1 & $\begin{array}{l}\text { Cruozon } \\
\text { syndrome }\end{array}$ & 7 & $\mathrm{f}$ & + & & & \\
\hline 2 & $\begin{array}{l}\text { Cruozon } \\
\text { syndrome }\end{array}$ & 3 & $\mathrm{~m}$ & + & & & \\
\hline 3 & $\begin{array}{l}\text { Cruozon } \\
\text { syndrome }\end{array}$ & 10 & $\mathrm{~m}$ & + & & & \\
\hline 4 & $\begin{array}{c}\text { Nasal } \\
\text { adhesions }\end{array}$ & 2 & $\mathrm{~m}$ & & & & \\
\hline 5 & $\begin{array}{c}\text { Nasal } \\
\text { adhesions }\end{array}$ & 3 & $\mathrm{f}$ & + & $\begin{array}{l}\text { Allar collapse } \\
\text { choanal } \\
\text { stenosis }\end{array}$ & + & \\
\hline 6 & $\begin{array}{c}\text { Nasal } \\
\text { adhesions }\end{array}$ & 4 & $\mathrm{f}$ & + & & & \\
\hline 7 & $\begin{array}{c}\text { Nasal } \\
\text { adhesions }\end{array}$ & 1 & $\mathrm{~m}$ & + & & + & recurrence \\
\hline 8 & $\begin{array}{c}\text { Nasal } \\
\text { adhesions }\end{array}$ & 7 & $\mathrm{f}$ & & & + & \\
\hline 9 & $\begin{array}{c}\text { Nasal } \\
\text { adhesions }\end{array}$ & 3 & $\mathrm{f}$ & + & & & \\
\hline 10 & $\begin{array}{c}\text { Nasal } \\
\text { adhesions }\end{array}$ & 19 & $\mathrm{~m}$ & & & & \\
\hline 11 & $\begin{array}{c}\text { Nasal } \\
\text { adhesions }\end{array}$ & 5 & $\mathrm{~m}$ & + & & & \\
\hline 12 & $\begin{array}{c}\text { Nasal } \\
\text { adhesions }\end{array}$ & 3 & $\mathrm{f}$ & & & & \\
\hline 13 & $\begin{array}{c}\text { Nasal } \\
\text { adhesions }\end{array}$ & 12 & $\mathrm{f}$ & + & & & \\
\hline 14 & CPAS & 3 & $\mathrm{f}$ & & & & \\
\hline
\end{tabular}
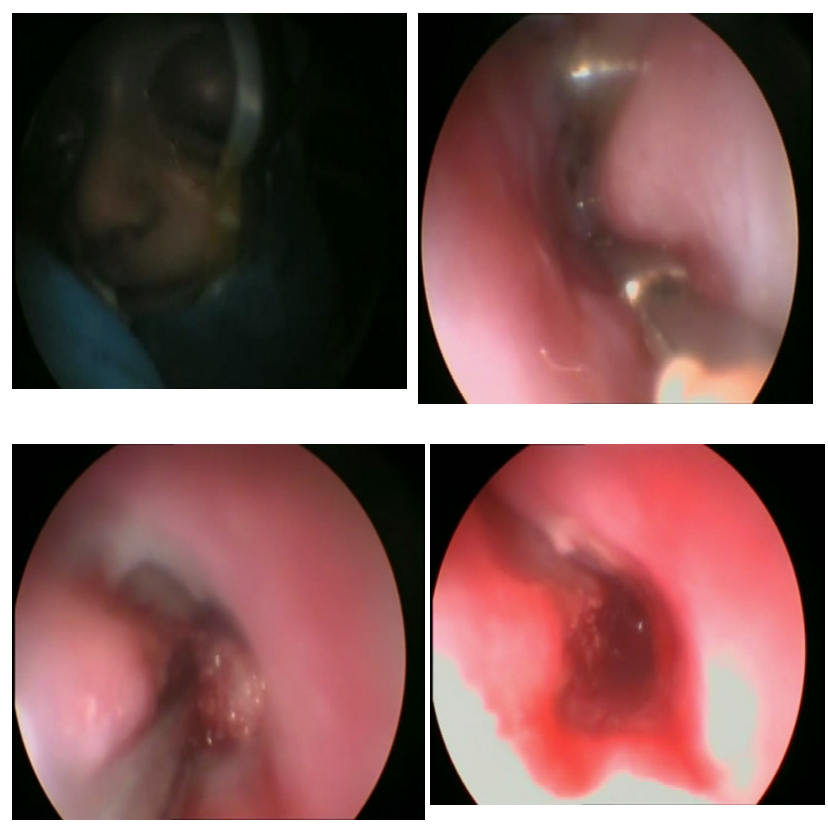

Fig. 1: endoscopic infantile nasal surgery in Crouzon syndrome (a), cautery by coblation (b), sharp cutting of inferior turbinate (c), and widening of the nasal airway after partial turbinectomy (d).

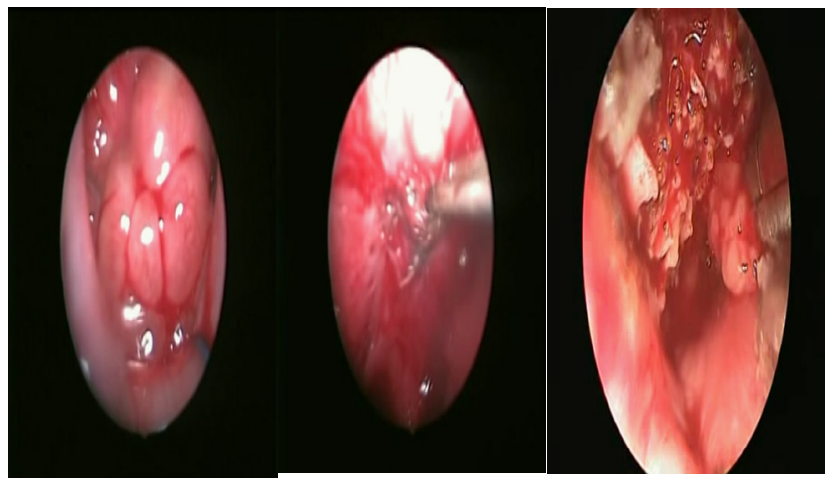

Fig. 2: endoscopic assisted adenoidectomy, nasopharyngeal view pre excision (a) and post excision (b), transnasal choanal adenoid excision (c). 

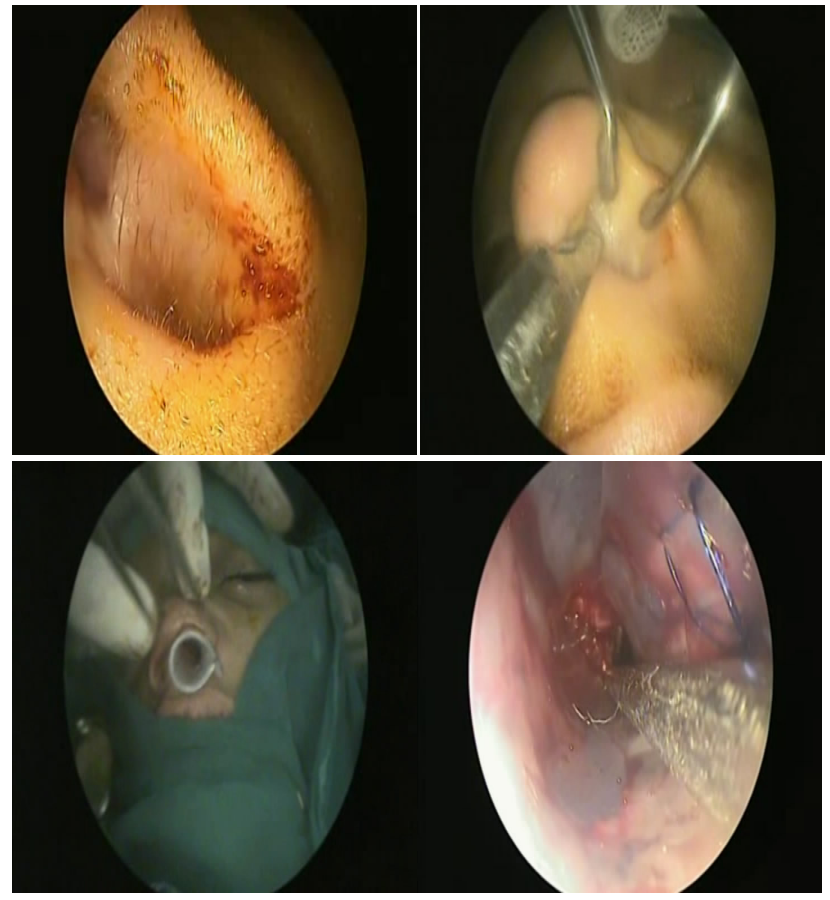

Fig. 3: Iaterogenic anterior nasal adhesion incomplete (a), complete (b), Silicone sheet stents (c), and endoscopic view through stent after adhesolysis (d).

\section{DISCUSSION}

Neonatal airway obstruction could be nasal (choanal atresia), craniofacial syndromes (Crouzon syndrome, Pierre-Robin syndrome), glossal (Down syndrome), or laryngeal (laryngomalacia, vocal cord palsy), or lower developmental problems (tracheo/ bronchomalacia) $)^{[1]}$. Neonatal nasal obstruction is mostly due to neonatal rhinitis, viral upper respiratory tract infections, and possibly milk/soy allergies ${ }^{[7]}$. Other causes for neonatal nasal obstruction are more rarely met which include choanal atresia (the most common congenital nasal disease), choanal stenosis, congenital nasal mid-line masses, congenital nasal pyriform aperture stenosis, and nasal tip anomalies ${ }^{[8]}$. Proper early assessment and management of neonatal respiratory obstruction are necessary after securing the airway. Treatment options include simple observation, conservative management, and surgery (immediate or delayed $)^{[1]}$.

Infantile nasal blockage is not uncommon presentation in the first year of life; parents complained that the infant has blocked nose, snoring, difficult suckling, sometimes chocking and respiratory obstruction and cyanosis. In neonates the inability to remove nasal secretion by nose blowing with nasal obstruction can cause serious consequences as respiratory distress or discomfort, sleep disturbance, and feeding difficulties ${ }^{[7]}$. Complications of severe nasal blockage in infants may include pneumonia, failure to thrive, core pulmonale, and sudden infant death syndrome.
Crouzon syndrome is a syndrome characterized by orofacial manifestations as maxillary hypoplasia, external nasal deformity, and prognathism, due to premature closure of craniofacial sutures. Upper nasal obstruction in Crouzon syndrome is attributed to septal deviation, midnasal and choanal abnormalities, and nasopharyngeal narrowing ${ }^{[3]}$. In this study correction of midnasal and choanal narrowing through endoscopic inferior turbinate reduction and adenoidectomy revealed to be effective in treating the upper airway obstruction in those patients, although long term follow up is recommended with the possibility of staged surgical interference for maxillofacial deformity.

Iaterogenic nasal stenosis is a rare complication following supportive care in premature infants. Early diagnosis and management of neonatal iaterogenic nasal stenosis can reduce complications ${ }^{[4]}$. Also, nasal continuous positive airway pressure (nCPAP) carries a small risk of irreversible nasal ischemia and necrosis due to the configuration of the pressure delivery system ${ }^{[9]}$. In this study all infants had nasal maneuvers (nasogastric feeding, nasal suctioning and nasal continuous positive airway pressure) during their neonatal care period. Careful management of neonatal nasal obstruction is very important to avoid unnecessary complications as nasal synechia, vestibular stenosis, alar and collamellar necrosis.

Treatment options of iaterogenic nasal adhesions include endoscopic synechiolysis result in partial improvement and required multiple procedures to get better results ${ }^{[10]}$. In other study, endoscopic synechiolysis with nasal stenting and application of Mitomycin $\mathrm{C}$ gives better result ${ }^{[4]}$. In this study, endoscopic nasal adhesolysis was done using coblation needle and bipolar diathermy without extensive cauterization with correction of associated pathology. Most instruments used were micro otologic instruments. Stents were reserved for complete and or anterior adhesions ( 4 cases) to avoid post operative scarring and vestibular adhesions. All patients improved postoperatively except one had restenosis and lost for follow up.

Congenital nasal pyriform aperture stenosis (CNPS) is a rare cause of neonatal nasal obstruction. Stenosis of the anterior third of the nasal cavity is due to excessive growth of the nasal process of the maxilla ${ }^{[11]}$. CNPS may be isolated or combined with other cranial-facial malformation $^{[12]}$. CNPS is diagnosed clinically by difficulty to pass a small catheter though the anterior nasal valve and confirmed with CT scan. A pyriform aperture width of less than $5.7 \mathrm{~mm}$ in a neonate is $88 \%$ sensitive in predicting surgical intervention ${ }^{[13]}$. Sublabial surgical correction of the CNPS with nasal stenting was very successful option ${ }^{[12]}$. Other study showed that CNPS was successfully treated with nasal 
dilation by cervical hegar dilators without pyriform aperture bone removal or nasal stenting ${ }^{[14]}$. In this study trans nasal endoscopic approach in correction of CNPS revealed to be safe, easy and effective technique.

Although choanal atresia repair is the most common endoscopic nasal procedure in the infantile age group other indications need proper diagnosis and management. Meticulous handling of neonates diagnosed with nasal obstruction is important to decrease the risk of iatrogenic injuries and complications. Infantile endoscopic nasal surgery is difficult procedure regarding the delicate anatomy, precise minimal surgical technique, and post operative healing processes which can cause inevitable operative sequel in the form of restenosis, and adhesions. Proper knowledge and experience with endoscopic surgery in this age is mandatory as regard preoperative preparation and planning, operative technique, and post operative follow up. In this study, endoscopic infantile nasal surgery was safe, effective, easily replicable in various indications of infantile nasal obstruction, and although the technique is challenging and required good experience yet it is rewarding and mostly successful.

\section{CONFLICT OF INTEREST}

There are no conflicts of interest.

\section{CONCLUSION}

Various non atretic indications for infantile endoscopic surgery as nasal adhesions, nasal obstruction in crouzon syndrome and CPAS could properly managed with endoscopic surgery. Careful management of nasal obstruction during neonatal care with delicate handling is very important to avoid unnecessary complications as nasal adhesions. Proper knowledge and experience with endoscopic surgery in this age is mandatory regarding the preoperative preparation and planning, operative technique, and post operative follow up. The technique is challenging and required good experience yet it is rewarding and mostly successful.

\section{REFERENCES}

1. Lyons M, Vlastarakos PV, Nikolopoulos TP. Congenital and acquired developmental problems of the upper airway in newborns and infants. Early Hum Dev. 2012 Dec; 88(12):951-5.

2. Rodríguez $\mathrm{H}$, Cuestas $\mathrm{G}$, Rodríguez $\mathrm{D}$ Aquila M, Rodríguez D Aquila JA. [Algorithm for the management of nasal obstruction in neonates and infants]. Arch Argent Pediatr. 2016 Oct 1; 114(5): 477-84.
3. Sirotnak J, Brodsky L, Pizzuto M. Airway obstruction in the Crouzon syndrome: case report and review of the literature. Int J Pediatr Otorhinolaryngol. 1995 Mar; 31(2-3):235-46.

4. Smith LP, Roy S. Treatment strategy for iatrogenic nasal vestibular stenosis in young children. Int $\mathrm{J}$ Pediatr Otorhinolaryngol. 2006 Aug; 70(8):1369-73. Epub 2006 Mar 27.

5. Zanetta A, Rodríguez H, Cuestas G, Tiscornia C. [Stertor in the newborn due to congenital nasal pyriform aperture estenosis: case series]. Arch Argent Pediatr. 2010 Dec; 108(6):552-5.

6. Hesham Mohammad Eladl, Yasser W. Khafagy. Endoscopic bilateral congenital choanal atresia repair of 112 cases, evolving concept and technical experience. International Journal of Pediatric Otorhinolaryngology 85 (2016) 40-45.

7. Chirico G, Beccagutti F. Nasal obstruction in neonates and infants. Minerva Pediatr. 2010 Oct; 62(5):499505.

8. Başal Y, Akcan AB, Polat YD, Günel C, Eryilmaz A, Başak S. Rarely Seen Nasal Congenital Problems Causing Neonatal Upper Respiratory Obstruction: A Case Series. Pediatr Rep. 2016 Mar 31; 8(1):6456.

9. Chao JW, Raveendran JA, Sauerhammer TM, Rogers GF, Oh AK, Boyajian M. Columellar Reconstruction after Nasal Continuous Positive Airway Pressure Associated Necrosis. J Craniofac Surg. 2017 Jun; 28(4):928-930

10. DeRowe A, Landsberg R, Fishman G, Halperin D, Fliss D. Neonatal iatrogenic nasal obstruction. Int $\mathrm{J}$ Pediatr Otorhinolaryngol. 2004 May; 68(5):613-7.

11. Serrano TL, Pfeilsticker L, Silva V, Hazboun I, Paschoal J, Maunsell R, Sakano E. Newborn nasal obstruction due to congenital nasal pyriform aperture stenosis. Allergy Rhinol (Providence). 2016 Jan; 7(1):37-41.

12. Sesenna E1, Leporati M, Brevi B, Oretti G, Ferri A Congenital nasal pyriform aperture stenosis: diagnosis and management. Ital J Pediatr. 2012 Jun 26; 38:28.

13. Wormald R, Hinton-Bayre A, Bumbak P, Vijayasekaran S. Congenital nasal pyriform aperture stenosis 5.7 $\mathrm{mm}$ or less is associated with surgical intervention: A pooled case series. Int J Pediatr Otorhinolaryngol. 2015 Nov; 79(11):1802-5.

14. Wine TM, Dedhia K, Chi DH. Congenital nasal pyriform aperture stenosis: is there a role for nasal dilation? JAMA Otolaryngol Head Neck Surg. 2014 Apr; 140(4):352-6. 